\title{
Natural Background Level and Contamination of Shallow Groundwater Salinity in Various Aquifers in a Coastal Urbanized Area, South China
}

\author{
Pan Bi, ${ }^{1,2}$ Dongya Han $\mathbb{D}^{3},{ }^{3}$ Chunyan Liu, ${ }^{3}$ Liquan Xiao, ${ }^{4}$ Heqiu Wu, ${ }^{5}$ and Meng Zhang \\ ${ }^{1}$ School of Water Resources and Environment, Hebei GEO University, Shijiazhuang, China \\ ${ }^{2}$ Key Laboratory of Sustained Development and Utilization of Water Resources, Shijiazhuang, China \\ ${ }^{3}$ Institute of Hydrogeology and Environmental Geology, Chinese Academy of Geological Sciences, Shijiazhuang, China \\ ${ }^{4} 416$ Geological Team of Hunan Bureau of Geology and Mineral Exploration and Development, Zhuzhou, China \\ ${ }^{5}$ Zhejiang Engineering Geophysical Survey and Design Institute Co.,Ltd., Hangzhou, China \\ Correspondence should be addressed to Dongya Han; handongyaycn@126.com
}

Received 30 May 2021; Accepted 27 July 2021; Published 9 August 2021

Academic Editor: Chengcheng Li

Copyright (C) 2021 Pan Bi et al. This is an open access article distributed under the Creative Commons Attribution License, which permits unrestricted use, distribution, and reproduction in any medium, provided the original work is properly cited.

\begin{abstract}
Assessing natural background levels (NBLs) of chemical components in groundwater is useful for the evaluation of groundwater contamination in urbanized areas. The present study assessed the NBL of total dissolved solids (TDS) in various groundwater units in the Pearl River Delta (PRD) where urbanization is a large scale and discussed factors controlling groundwater salinity contamination in the PRD. Results showed that the NBL of TDS in groundwater in the coastal-alluvial plain was more than 1.5 times that in other groundwater units because of the seawater intrusion in this groundwater unit. By contrast, interactions of water and soils/rocks were the main factors controlling the NBLs of TDS in other groundwater units. Groundwater salinity contamination in the PRD was positively correlated with the urbanization level. Wastewater from township-village enterprises and industrial wastewater were likely to be the main sources for groundwater salinity contamination in the PRD. Moreover, the wastewater leakage from sewer systems was one of the main pathways for groundwater salinity contamination in urbanized areas, because the proportion of groundwater salinity contamination in urbanized areas formed in 1988-1998 was more than 1.5 times that in urbanized areas formed in 1998-2006 regardless of groundwater units. Besides, sewage irrigation and leakage of landfill leachate were also important sources for groundwater salinity contamination in the PRD.
\end{abstract}

\section{Introduction}

Groundwater plays a crucial role in our livelihoods by making itself available for drinking. For example, more than half of drinking water is sourced from groundwater globally [1]. However, groundwater is often contaminated due to the large-scale urbanization and industrialization in urbanized areas $[2,3]$; thereby, its quality in these areas is often deteriorated [4]. For instance, the Pearl River Delta (PRD) is a rapidly urbanized and industrialized area in China, and groundwater in this area is often contaminated by the salinity because of various anthropogenic sources such as high levels of salinity in wastewaters $[3,5]$. In addition, several studies reported that geogenic sources are mainly responsible for the origin of groundwater salinity in Quaternary aquifers in the PRD by using isotopic, hydrochemical, and microbial evidence [6-8]. However, the origins of groundwater salinity in fissured and karst aquifers as well as the spatial distribution of groundwater salinity contamination in the PRD are unclear. Thus, in order to improve the management and protection of groundwater resources, it is necessary to evaluate the status of groundwater salinity contamination and investigate the factors controlling groundwater salinity in the PRD.

To date, the evaluation of groundwater contamination is often based on the maximum admissible concentrations of chemical components which are harmless to human beings [9-11]. In this case, the impacts of natural factors on the 
concentrations of chemical components in groundwater are neglected. However, high levels of chemical components in groundwater may derive from not only anthropogenic contamination but also natural processes [12-15]. Therefore, it is more reasonable to evaluate the groundwater contamination based on natural background levels (NBLs) of chemical components in groundwater. Here, NBLs are defined as concentrations present in groundwater as controlled by natural geogenic, biological, and chemical processes [16]. Preselection is the most common method for the assessment of NBL in groundwater [17]. For example, the method of oxidation capacity (OXC), as one of the preselection methods, was often used to assess the groundwater NBL in coastal areas $[16,18]$.

Therefore, the objectives of this study are to assess the NBL of salinity (total dissolved solids, TDS) in the PRD by using the OXC method with Grubbs' test, to depict the spatial distribution of groundwater salinity contamination with a Kriging method and to discuss factors controlling groundwater salinity contamination in the PRD. The conclusions would be helpful for improving the management and protection of groundwater resources in the PRD.

\section{Study Area}

The PRD occupies a total area of $4.17 \times 10^{4} \mathrm{~km}^{2}$ in the southern part of Guangdong province, China. It includes nine cities, such as Guangzhou, Shenzhen, Foshan, Dongguan, Zhongshan, Zhuhai, Huizhou, Jiangmen, and Zhaoqing, in the district. It is bounded by hills in the east, west, and north and by the South China Sea in the south; thereby, its topography inclines from the east, west, and north to the south. Three major rivers, such as East River, West River, and North River, merge in the south and form the Pearl River, which finally discharges into the South China Sea. The PRD can be divided into three areas with different urbanization levels, such as urbanized area (UA), periurban area (PUA), and nonurbanized area (NUA) [13]. Besides, the UA in the PRD formed before 1988, from 1988 to 1998 , and from 1998 to 2006 are denoted by $\mathrm{UA}^{1 \mathrm{st}}, \mathrm{UA}^{2 \mathrm{nd}}$, and $\mathrm{UA}^{3 \mathrm{rd}}$, respectively. $\mathrm{UA}^{1 \mathrm{st}}$ is characterized by a lower proportion of factories in comparison with $\mathrm{UA}^{2 \text { nd }}$ and $\mathrm{UA}^{3 \text { rd }}$, while $\mathrm{UA}^{3 \mathrm{rd}}$ shows a relatively well-constructed sewer system in comparison with $\mathrm{UA}^{1 \text { st }}$ and $\mathrm{UA}^{2 \text { nd }}$ [5].

The PRD was formed as a result of the Tibetan Plateau uplift during the Tertiary and Quaternary Periods. It can be divided into four groundwater units (Figure 1). Unit A is related to a coastal-alluvial plain, which is located in the central and southern parts of the PRD and consists of two marine layers and two terrestrial layers [2]. The younger marine layer (M1) has an elevation of above $-20 \mathrm{~m}$, and the older marine layer (M2) is located between -15 and $-40 \mathrm{~m}$ (Figure 1). The younger terrestrial layer (T1) can be sandy fluvial deposits or clayey silt. The older terrestrial layer (T2) is dominated by sand and gravel [19]. Groundwater in this unit is recharged primarily by atmospheric precipitation, agricultural irrigation, and seawater intrusion [20,21]. Unit $\mathrm{B}$ (alluvial-proluvial aquifer) is outside of unit A, which is related to the valley and interhill plains where marine layers are absent but terrestrial layers are common. Unit C (fissured aquifer) is related to hilly areas where bedrocks are fractured. Unit D is related to karst aquifers and accounts for less than $10 \%$ of the total area [22].

\section{Materials and Methods}

3.1. Sampling and Analytical Techniques. Approximately 400 groundwater samples were collected from the PRD. Specifically, 124 samples, 134 samples, 132 samples, and 9 samples were collected from units A to D, respectively. All the samples were stored at $4^{\circ} \mathrm{C}$ until the laboratory procedures could be performed. Redox potential (Eh), $\mathrm{pH}$, and dissolved oxygen (DO) were measured on site using a multiparameter instrument (WTW Multi 340i/SET, Germany). Metals (K, $\mathrm{Na}, \mathrm{Ca}$, and $\mathrm{Mg}$ ) were measured by inductively coupled plasma mass spectrometry (Agilent 7500ce ICP-MS, Tokyo, Japan). $\mathrm{HCO}_{3}$ and TDS were measured using acid-base titration and gravimetric methods, respectively. $\mathrm{NH}_{4}$ and other anions $\left(\mathrm{NO}_{3}, \mathrm{SO}_{4}\right.$, and $\mathrm{Cl}$ ) were analyzed by ion chromatography (Shimadzu LC10ADvp, Japan). To ensure data quality, each sample was analyzed in triplicate, and sample batches were regularly interspersed with standards and blanks. The relative errors of inorganic parameters were $< \pm 5 \%$.

3.2. NBL Assessment. Griffioen et al. reported that oxidation capacity is calculated as $7\left[\mathrm{SO}_{4}\right]+5\left[\mathrm{NO}_{3}\right]$ with the concentration of the species in $[\mathrm{mmol} / \mathrm{L}][16]$. The oxidation capacity will be useless to identify groundwater with anthropogenic influence under the condition of a strongly reductive environment because groundwater $\mathrm{SO}_{4}$ and $\mathrm{NO}_{3}$ are at low levels. In this case, high levels of $\mathrm{NH}_{4}$ will be a useful indicator for the identification of contaminated groundwater, because high levels of $\mathrm{NH}_{4}$ in shallow groundwater in the PRD originated from human activities [23]. Therefore, a preselection method, consisting of two indicators such as the oxidation capacity and $\mathrm{NH}_{4}$ concentration, was used for the assessment of NBL in groundwater in this study. Specifically, groundwater samples with oxidation capacity $>3$ meq/L or $\mathrm{NH}_{4}-\mathrm{N}$ concentrations $>0.5 \mathrm{mg} / \mathrm{L}$ in original datasets were deleted, and the remaining datasets were denoted as PS datasets. Note that a higher value of $3 \mathrm{meq} / \mathrm{L}$ was selected as the threshold value for oxidation capacity in comparison with previous studies because geogenic sources are sometimes responsible for high levels of $\mathrm{SO}_{4}$ in groundwater in the PRD [24]. Then, TDS concentrations in PS datasets in various groundwater units were tested by Grubbs' test $(\alpha=0.01)$ until normal distributions were obtained, and the outliers in various groundwater units were deleted (Supplementary material, Section 3.2) [25]. The remaining datasets were denoted as residual datasets. The maximum concentrations of TDS in residual datasets in various groundwater units were extracted as NBLs.

3.3. Evaluation of Contamination Levels. In this study, the contamination level of salinity in groundwater was quantified by the ratios of groundwater TDS concentrations to the 


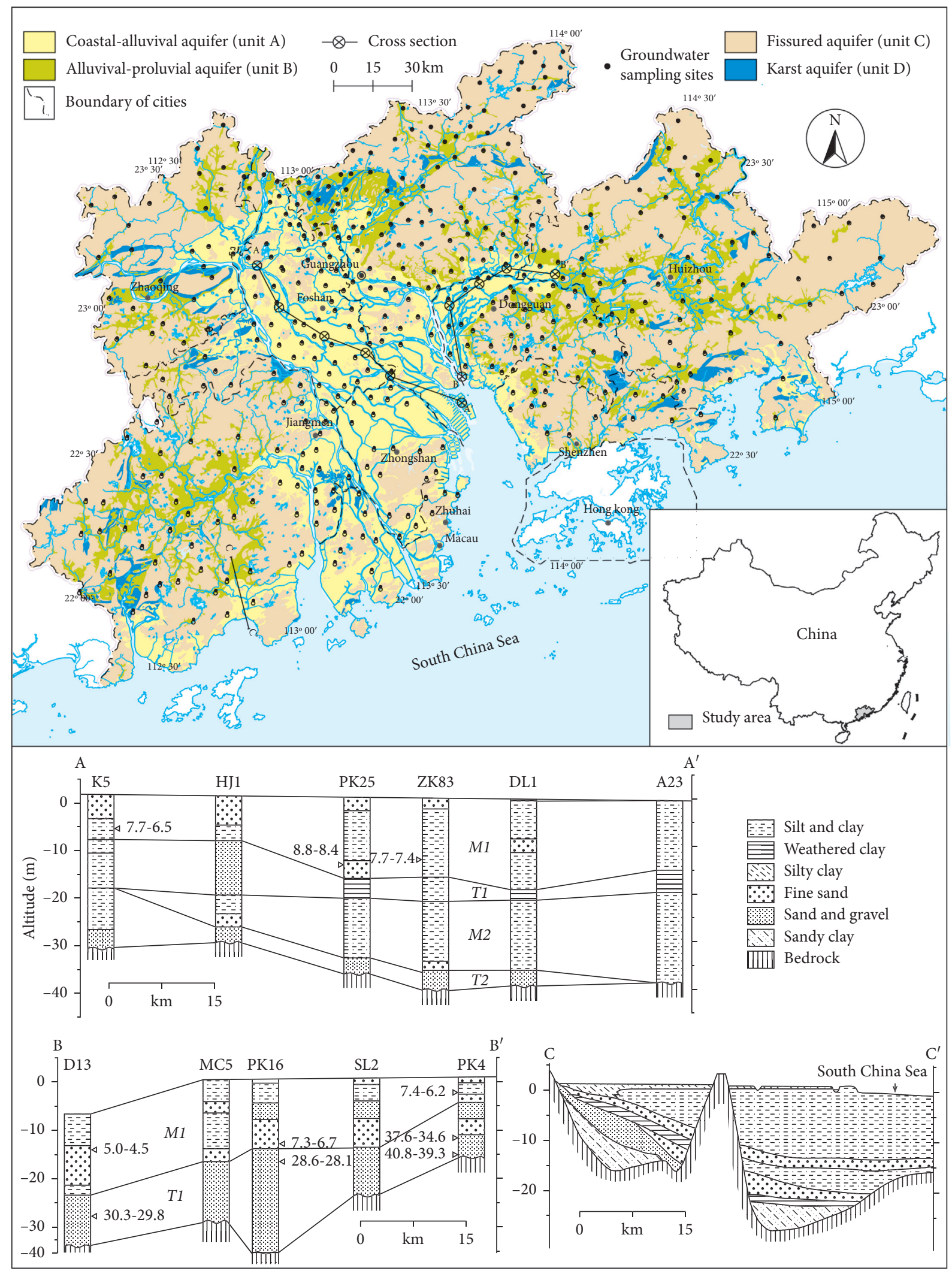

Figure 1: Groundwater units and sampling sites in the Pearl River Delta.

NBLs of TDS in various groundwater units. Thus, groundwater samples with different contamination levels are divided into four categories as follows: uncontaminated (contamination level $\leq 1)$, low $(1<$ contamination level $\leq 2)$, moderate $(2<$ contamination level $\leq 4)$, and high (contamination level $>4$ ). The spatial distribution of groundwater 
salinity contamination in the PRD is depicted by a geostatistical analysis (MapGIS 10.2, China University of Geosciences, China). The universal kriging method and the estimation of empirical semivariogram models are used in MapGIS 10.2 software [26, 27]. The details are in the supplementary material (Section 3.2).

3.4. Socioeconomic Data. Socioeconomic data related to nine major cities in the PRD were compiled and used in this study. Relevant data were taken from the Statistical Yearbook of Guangdong Province and are compiled in Table S1 [28]; they include population density (PD, number of people $/ \mathrm{km}^{2}$ ), gross domestic product (GDP, millions of Chinese yuan/ $\mathrm{km}^{2}$ ), domestic sewage discharge (DSD, ton $/ \mathrm{km}^{2}$ ), industrial wastewater discharge (IWD, ton $/ \mathrm{km}^{2}$ ), ratio of urbanized areas (RUA, \%), industrial enterprises above a specified size (IE, number $/ \mathrm{km}^{2}$ ), township-village enterprises (TVEs, number $/ \mathrm{km}^{2}$ ), agricultural output ( $\mathrm{AO}$, millions of Chinese yuan $/ \mathrm{km}^{2}$ ), livestock output (LO, millions of Chinese yuan/ $\mathrm{km}^{2}$ ), and livestock density (LD, number $/ \mathrm{km}^{2}$ ).

3.5. Principal Components Analysis (PCA). The PCA is a useful technique for reducing a large number of variables to a small number of principal components (i.e., PCs) by linearly combining measurements made on the original variables [13]. In this study, the PCA was used to identify the relationships between the contamination level of groundwater salinity and the relevant socioeconomic data. In the PCA, only PCs with eigenvalues greater than one were retained for analyses, and the Varimax method was adopted. The terms "strong," "moderate," and "weak," as applied to PC loadings, referred to absolute loading values of $>0.75$, $0.75-0.5$, and $0.5-0.3$, respectively [2].

\section{Results}

4.1. NBL Assessment for Groundwater Salinity. Using oxidation capacity $>3 \mathrm{meq} / \mathrm{L}$ and $\mathrm{NH}_{4}-\mathrm{N}$ concentrations $>0.5 \mathrm{mg} / \mathrm{L}$ to identify groundwater samples with anthropogenic influence in this study, nearly $60 \%$ of groundwater samples with anthropogenic influence in original datasets were removed out (Figure 2), and the remaining datasets were denoted as PS datasets. Then, TDS concentrations in PS datasets in various groundwater units were tested by Grubbs' test $(\alpha=0.01)$, and outliers in PS datasets were eliminated (Figure 3). The remaining datasets were denoted as residual datasets. The maximum concentrations of TDS in residual datasets in various groundwater units are extracted as NBLs; thereby, NBLs of TDS in units A to D were $688 \mathrm{mg} / \mathrm{L}$, $432 \mathrm{mg} / \mathrm{L}, 321 \mathrm{mg} / \mathrm{L}$, and $99 \mathrm{mg} / \mathrm{L}$, respectively.

\subsection{Distribution of Groundwater Salinity Contamination in the $P R D$}

4.2.1. Salinity Contamination in Various Groundwater Units. As shown in Table 1, 21.1\% of groundwater samples in the PRD were contaminated by salinity. Among them, low to high contamination levels of groundwater samples

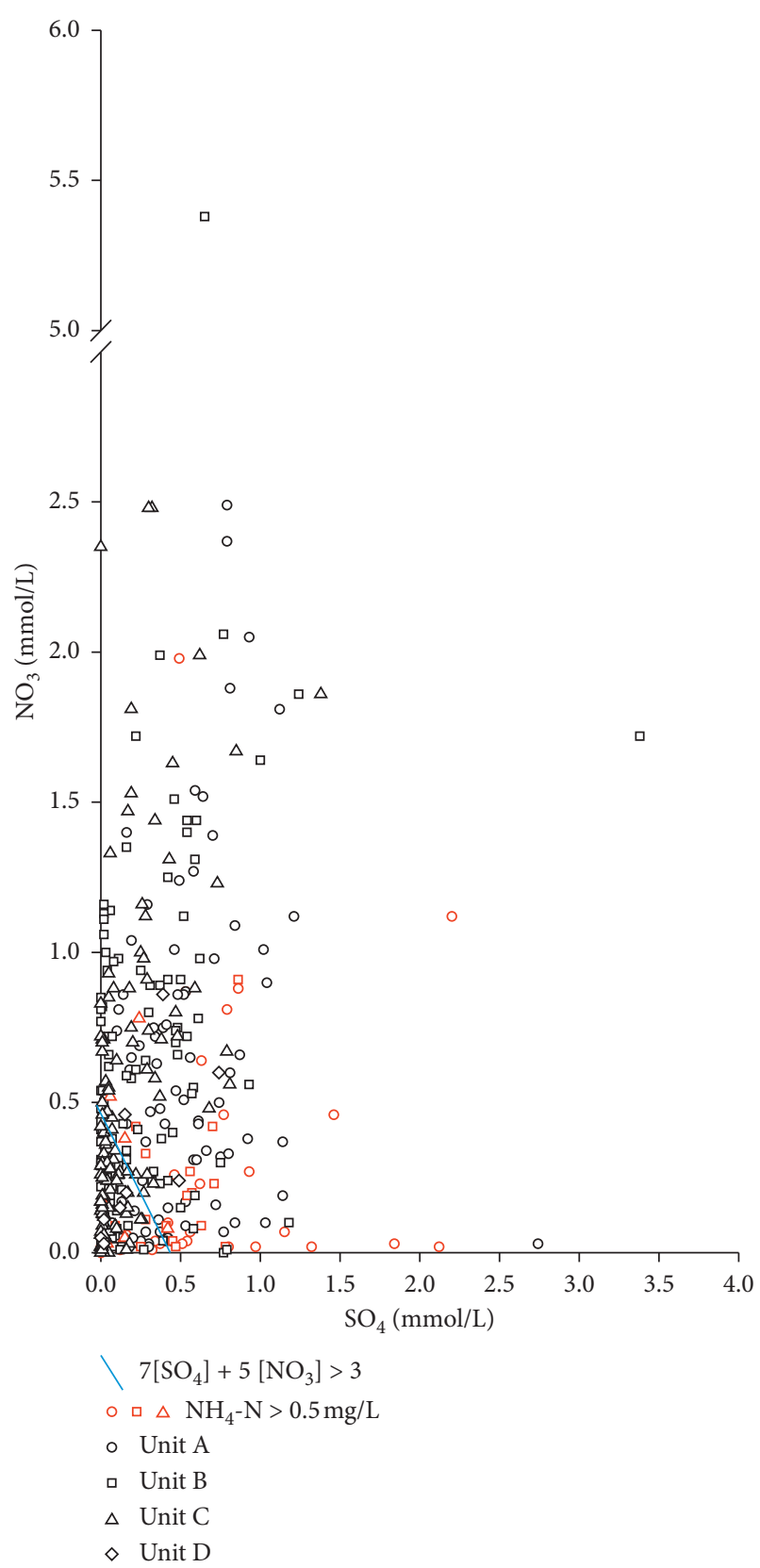

FIgURE 2: High levels of $\mathrm{NH}_{4}$ as well as oxidation capacity in various groundwater units in the Pearl River Delta.

accounted for $16.5 \%, 3.8 \%$, and $0.8 \%$, respectively. Salinity contamination in various groundwater units in the PRD was significantly different. High levels of salinity contamination occurred in groundwater units $\mathrm{A}$ and $\mathrm{B}$, but not in units C and D. By contrast, moderate levels of salinity contamination in groundwater unit $\mathrm{D}$ accounted for $44.4 \%$, which was 10 times that in unit $C$ and 20 times that in units A and B. Meanwhile, a low level of salinity contamination in groundwater unit A accounted for $26.6 \%$ and was more than 2 times that in other groundwater units. As far as the proportion of salinity contamination is concerned, groundwater unit $\mathrm{D}$ was the highest, which was 1.8 times that in unit A and 3.6 times that in units B and C. 


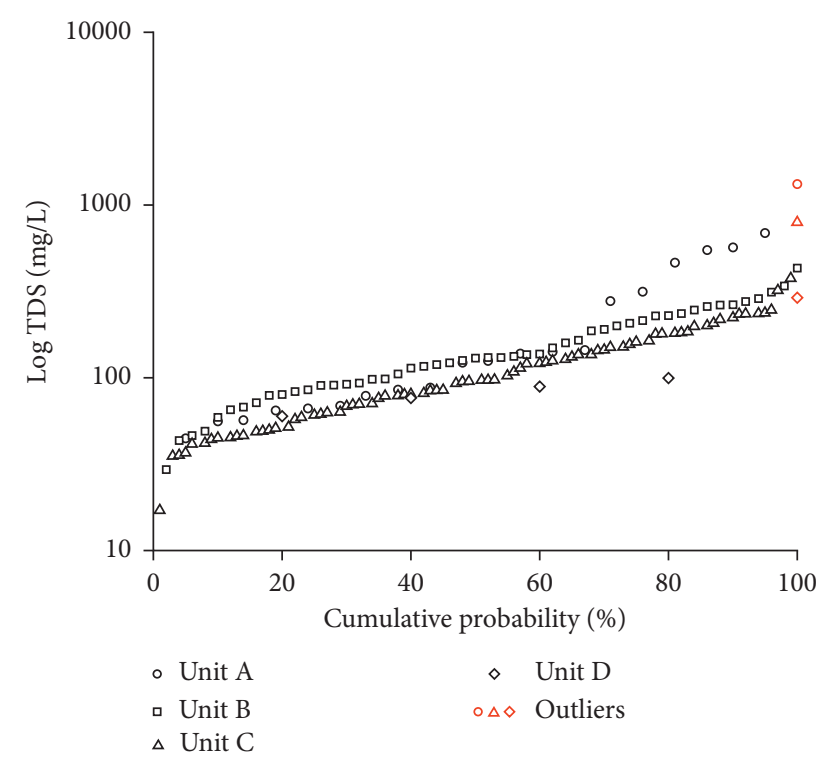

FIGURE 3: Outliers in PS datasets in various groundwater units tested by Grubbs' test.

TABLE 1: Groundwater salinity contamination in various groundwater units in the Pearl River Delta.

\begin{tabular}{lccccc}
\hline Contamination levels & PRD & Unit A & Unit B & Unit C & Unit D \\
\hline Uncontaminated (\%) & 78.9 & 69.4 & 84.7 & 84.8 & 44.5 \\
Low (\%) & 16.5 & 26.6 & 12.4 & 11.4 & 11.1 \\
Moderate (\%) & 3.8 & 2.4 & 2.2 & 3.8 & 44.4 \\
High (\%) & 0.8 & 1.6 & 0.7 & 0 & 0 \\
\hline
\end{tabular}

4.2.2. Groundwater Salinity Contamination in Areas with Different Urbanization Levels. As seen in Table 2, the proportion of groundwater salinity contamination in UA was $29.7 \%$, which was 1.2 times and 3.3 times that in PUA and NUA, respectively. This indicates that groundwater salinity contamination in the PRD was positively correlated with the urbanization level. Similarly, in groundwater unit A, the proportion of salinity contamination in UA was 1.8 times and 2.3 times that in PUA and NUA, respectively. Likewise, in groundwater unit $\mathrm{B}$, the proportion of salinity contamination in UA was 1.2 times and 9.1 times that in PUA and NUA, respectively. By contrast, in groundwater unit $C$, the proportion of salinity contamination in PUA was the highest, which was 1.6 times and 3.9 times that in UA and NUA, respectively. This indicates that the correlation between the salinity contamination and the urbanization level in groundwater unit $\mathrm{C}$ was insignificant. Note that the salinity contamination in areas with different urbanization levels in groundwater unit D was not investigated because of too few samples. In addition, groundwater salinity contamination in UA formed in different periods in the PRD was also investigated. In groundwater unit A, proportions of salinity contamination in $\mathrm{UA}^{1 \text { st }}$ and $\mathrm{UA}^{2 \text { nd }}$ were close to each other and were approximately 1.5 times that in $\mathrm{UA}^{3 \mathrm{rd}}$ (Table S2). By contrast, the proportion of salinity contamination in groundwater unit $\mathrm{B}$ in $\mathrm{UA}^{2 \text { nd }}$ was the highest and was more than 5 times and 2 times that in $\mathrm{UA}^{1 \mathrm{st}}$ and $\mathrm{UA}^{3 \mathrm{rd}}$, respectively (Table S2). Similarly, the proportion of salinity contamination in groundwater unit $\mathrm{C}$ in $\mathrm{UA}^{2 \text { nd }}$ was also much higher than that in $\mathrm{UA}^{1 \text { st }}$ and $\mathrm{UA}^{3 \mathrm{rd}}$ (Table S2).

4.2.3. Spatial Distribution of Groundwater Salinity Contamination in Various Cities. As shown in Table 3, the high level of groundwater salinity contamination occurred in Dongguan and Guangzhou cities only, which accounted for less than $1 \%$ of the total area (Figure 4 ). The moderate level of groundwater salinity contamination occurred in six cities except for Shenzhen, Zhuhai, and Zhaoqing, which accounted for approximately $5 \%$ of the total area (Figure 4 ). Among them, the occurrence of a moderate level of groundwater salinity contamination was mainly distributed in Dongguan and Zhongshan cities (Table 3). By contrast, the low level of groundwater salinity contamination occurred in all of the nine cities, which accounted for approximately $16 \%$ of the total area (Figure 4 ). As far as the proportion of groundwater salinity contamination is concerned, Zhongshan was the highest, which was followed by the order of Dongguan, Foshan, Guangzhou, Jiangmen, Huizhou, Shenzhen, Zhuhai, and Zhaoqing, respectively (Table 3).

4.3. Relationship between Contamination Levels of Groundwater Salinity and Socioeconomic Parameters. In this study, the relationship between the proportions of groundwater salinity contamination and socioeconomic parameters in various cities in the PRD was investigated by the PCA. Note that differences in the socioeconomic parameters of the cities resulting from differences in size were eliminated by using the values of the socioeconomic parameters per square kilometer $[3,5]$. PC2 shows strong positive loadings with the proportion of groundwater salinity contamination, TVE, and IWD (Table 4).

\section{Discussions}

5.1. Natural Factors Controlling Salinity in Various Groundwater Units. Generally, after the exclusion of the influence of anthropogenic activities, TDS in groundwater originates from the seawater intrusion, the soil-water interaction, and the rock-water interaction $[7,29]$. In this study, NBL-TDS in groundwater unit A was much higher than that in other groundwater units (Figure 3). This probably ascribes to seawater intrusion, because the intrusion of seawater with extremely high levels of TDS often occurs in groundwater unit A [21]. NBL-TDS in groundwater unit B was lower than that in groundwater unit A but much higher than that in the other two groundwater units (Figure 3 ). This may be attributed to the more strong interactions of water and soils/rocks in groundwater unit $\mathrm{B}$ in comparison with that in groundwater units $C$ and $D$ because the groundwater flow rate in unit $B$ is slower in comparison with that in units $\mathrm{C}$ and $\mathrm{D}$ [22]. This is also likely to be the main reason for the much higher NBL-TDS in groundwater unit $\mathrm{C}$ than that in groundwater unit $\mathrm{D}$. 
Table 2: Groundwater salinity contamination in areas with different urbanization levels in the Pearl River Delta.

\begin{tabular}{|c|c|c|c|c|c|c|c|c|c|c|c|c|}
\hline \multirow{2}{*}{ Contamination levels } & \multicolumn{3}{|c|}{ PRD } & \multicolumn{3}{|c|}{ Unit A } & \multicolumn{3}{|c|}{ Unit B } & \multicolumn{3}{|c|}{ Unit $\mathrm{C}$} \\
\hline & UA & PUA & NUA & UA & PUA & NUA & UA & PUA & NUA & UA & PUA & NUA \\
\hline Uncontaminated (\%) & 70.3 & 75 & 90.9 & 57.4 & 76.8 & 81.5 & 77.3 & 80.5 & 97.5 & 80 & 68.4 & 91.8 \\
\hline Low $(\%)$ & 24.3 & 18.5 & 7.0 & 40.7 & 18.6 & 11.1 & 17 & 17.1 & 2.5 & 12.5 & 21.1 & 8.2 \\
\hline Moderate (\%) & 4.7 & 5.6 & 1.4 & 1.9 & 2.3 & 3.7 & 3.8 & 2.4 & 0 & 7.5 & 10.5 & 0 \\
\hline High $(\%)$ & 0.7 & 0.9 & 0.7 & 0 & 2.3 & 3.7 & 1.9 & 0 & 0 & 0 & 0 & 0 \\
\hline
\end{tabular}

TABLe 3: Groundwater salinity contamination in various cities in the Pearl River Delta.

\begin{tabular}{lccccccccc}
\hline Contamination levels & Guangzhou & Shenzhen & Foshan & Dongguan & Huizhou & Zhaoqing & Jiangmen & Zhuhai & Zhongshan \\
\hline Uncontaminated (\%) & 79.3 & 86.7 & 75.8 & 65 & 84.4 & 96.2 & 80.9 & 92.3 & 52.7 \\
Low (\%) & 16.5 & 13.3 & 21 & 20 & 12.5 & 3.8 & 15.9 & 7.7 & 36.8 \\
Moderate (\%) & 2.1 & 0 & 3.2 & 12.5 & 3.1 & 0 & 3.2 & 0 & 10.5 \\
High (\%) & 2.1 & 0 & 0 & 2.5 & 0 & 0 & 0 & 0 & 0 \\
\hline
\end{tabular}
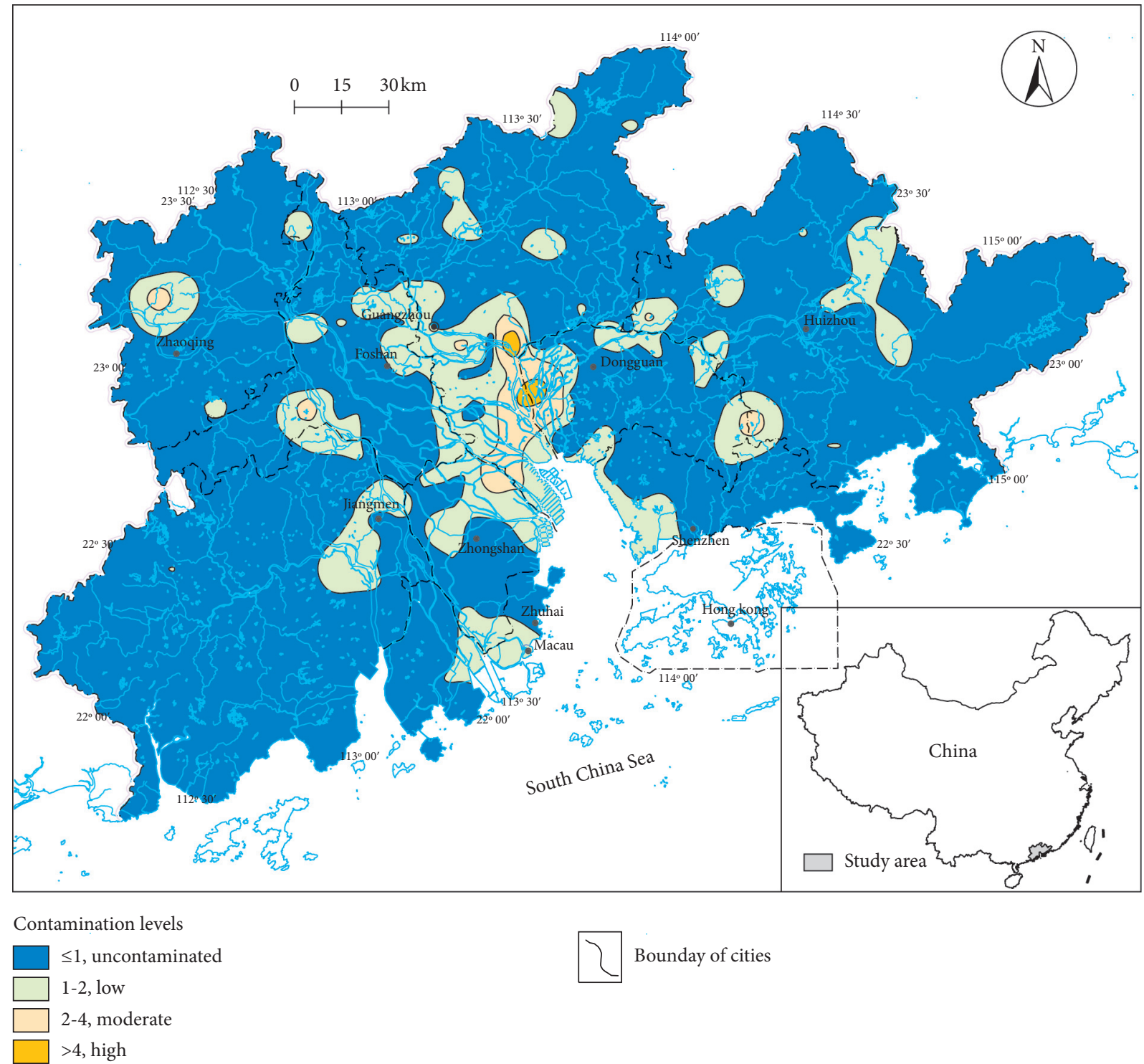

Bounday of cities

FIgURe 4: Spatial distribution of groundwater salinity contamination in the Pearl River Delta. 
TABle 4: Principal component (PC) loadings for proportions of groundwater salinity contamination and socioeconomic parameters in various cities in the Pearl River Delta

\begin{tabular}{lcccc}
\hline \multirow{2}{*}{ Items } & \multicolumn{4}{c}{ PCs } \\
& PC1 & PC2 & PC3 & PC4 \\
\hline GDP & $\mathbf{0 . 9 9 0}$ & -0.06 & -0.051 & -0.057 \\
DSD & $\mathbf{0 . 9 7 5}$ & 0.07 & 0.055 & -0.188 \\
PD & $\mathbf{0 . 9 6 6}$ & 0.16 & -0.136 & -0.109 \\
RUA & $\mathbf{0 . 9 4 0}$ & 0.062 & -0.243 & 0.019 \\
IE & $\mathbf{0 . 8 3 3}$ & 0.482 & -0.159 & 0.13 \\
PGSC & 0.095 & $\mathbf{0 . 9 5 6}$ & 0.104 & 0.136 \\
TVE & -0.075 & $\mathbf{0 . 9 4 3}$ & 0.111 & -0.276 \\
IWD & 0.386 & $\mathbf{0 . 8 1 9}$ & -0.247 & 0.081 \\
LO & -0.051 & -0.113 & $\mathbf{0 . 9 7 6}$ & -0.098 \\
AO & -0.207 & 0.153 & $\mathbf{0 . 9 4 9}$ & -0.008 \\
LD & -0.142 & -0.017 & -0.083 & $\mathbf{0 . 9 8 5}$ \\
Eigenvalue & 4.7 & 2.8 & 2.1 & 1.1 \\
Explained variance (\%) & 42.4 & 25.3 & 18.7 & 10.5 \\
Cumulative \% of variance & 42.4 & 67.7 & 86.4 & 96.8 \\
\hline
\end{tabular}

${ }^{a}$ PGSC: proportion of groundwater salinity contamination. Bold numbers represent maximum absolute PC loading of one parameter.

The proportions of salinity contamination in various groundwater units were significantly different (Table 1), indicating that groundwater salinity contamination in the PRD is affected by natural factors. A much higher proportion of salinity contamination in groundwater unit $\mathrm{D}$ than that in other groundwater units indicates that groundwater unit $\mathrm{D}$ has a higher risk of groundwater salinity contamination in comparison with other groundwater units in the PRD (Table 1) because the vadose zone in groundwater unit D is commonly characterized by more coarse-grained media in comparison with other groundwater units [22]. In addition, the proportion of salinity contamination in groundwater unit A was approximately 2 times that in groundwater units B and C (Table 1). This may not ascribe to natural factors but anthropogenic factors. In theory, the proportion of salinity contamination in groundwater unit A should be lower than that in groundwater units B and C if groundwater salinity contamination in various units is controlled by the property of media of vadose zone, because vadose zone in groundwater unit $\mathrm{A}$ is characterized by more fine-grained media in comparison with groundwater units B and C [22], which will result in the lower groundwater vulnerability of groundwater unit $\mathrm{A}$ in comparison with groundwater units $\mathrm{B}$ and $\mathrm{C}$ in the $\mathrm{PRD}$. On the other hand, the ratio of UA in groundwater unit A was much higher than that in groundwater units B and C (Figures 1 and S1), and UA was commonly accompanied by more factories and industrial wastewater in comparison with other areas [5]. Thus, it can be concluded that a higher ratio of UA in groundwater unit A than that in groundwater units B and $\mathrm{C}$ is likely to be responsible for the higher proportion of salinity contamination in groundwater unit A in comparison with that in groundwater units B and C.

5.2. Anthropogenic Factors Controlling Groundwater Salinity Contamination in the PRD. A much higher proportion of groundwater salinity contamination in UA than that in PUA and NUA indicates that human activities during urbanization should be the main factors (Table 2). Groundwater contamination such as nitrate and phosphorus contaminations in urbanized areas resulting from human activities was often identified by various socioeconomic parameters $[3,5]$. Therefore, the relationship between the proportions of groundwater salinity contamination and socioeconomic parameters in various cities in the PRD was investigated by the PCA, to identify which human activities mainly result in groundwater salinity contamination in the PRD. As shown in Table 4, the proportion of groundwater salinity contamination is accompanied by TVE and IWD in the same PC. This indicates that wastewater from TVE and industrial wastewater is probably the main sources of groundwater salinity contamination in the PRD on a regional scale because industrial wastewater and wastewater from TVE with high levels of TDS were sometimes illegally discharged into rivers or ground surface without treatment [20]. For instance, the amounts of TVE in Zhongshan and Dongguan were more than 3 times that in other cities (Table S1), and the industrial wastewater discharges in Zhongshan and Dongguan were also significantly higher than those in other cities (except for Foshan) (Table S1). Correspondingly, the proportions of groundwater salinity contamination in both Zhongshan and Dongguan were more than 1.4 times that in other cities (Table 3). By contrast, the amount of industrial wastewater discharge in Zhaoqing was markedly lower than that in other cities (Table S1). Correspondingly, the proportion of groundwater salinity contamination in Zhaoqing was significantly lower than that in other cities (Table 3 ). This is also supported by the evidence that the proportions of groundwater salinity contamination in $\mathrm{UA}^{\text {st }}$ were much lower than those in $\mathrm{UA}^{2 \text { nd }}$ and $\mathrm{UA}^{3 \mathrm{rd}}$ in some groundwater units such as B and C (Table S2) because $\mathrm{UA}^{\text {1st }}$ has a lower proportion of factories as well as a lower discharge of industrial wastewater in comparison with $\mathrm{UA}^{2 \mathrm{nd}}$ and $\mathrm{UA}^{3 \mathrm{rd}}$ [5]. In addition, the proportions of groundwater salinity contamination in various units in $\mathrm{UA}^{2 \text { nd }}$ were more than 1.5 times those in $\mathrm{UA}^{3 \mathrm{rd}}$ (Table S2), indicating that the wastewater leakage from sewer systems may be one of the main pathways for groundwater salinity contamination in $\mathrm{UA}$ in the PRD because $\mathrm{UA}^{3 \mathrm{rd}}$ shows a relatively wellconstructed sewer system in comparison with $\mathrm{UA}^{2 \mathrm{nd}}[5]$.

The proportions of groundwater salinity contamination in PUA were significantly higher than those in NUA in various groundwater units (Table 2). This is probably attributed to the infiltration of industrial wastewater and domestic sewage. On one hand, illegal discharge of industrial wastewater with high levels of TDS from factories into the nearby ground surface sometimes occurred in PUA but none in NUA because some factories such as TVE were distributed in PUA but none in NUA $[12,13]$. On the other hand, domestic sewage with high levels of TDS was also often discharged into the nearby ground surface in PUA in the PRD because a large number of people lived in the PUA where the sewer system was sometimes missing $[2,5]$. Therefore, the infiltration of industrial wastewater and domestic sewage is likely to be the main source of groundwater salinity contamination in PUA in the PRD. 
Though the proportion of groundwater salinity contamination in NUA was much lower than that in UA and PUA, it was still considerable, especially in groundwater unit A (Table 2). As shown in Figures 4 and S1, NUA contaminated by groundwater salinity was mainly located at a river network area adjacent to the Pearl River Estuary. This indicates that sewage irrigation may be mainly responsible for groundwater salinity contamination in NUA in the PRD. On one hand, most rivers in this river network area were contaminated by industrial and domestic sewage due to urbanization and industrialization, thereby resulting in high levels of TDS occurring in these polluted river waters [30]. On the other hand, agricultural lands within NUA near rivers were often irrigated by river waters $[4,20]$. Besides, a few groundwater samples characterized by relatively high levels of TDS within NUA were near landfills such as Datianshan landfill and Hongmei town landfill [5, 31], and these groundwater samples in the west boundary of Dongguan city and southeast of Guangzhou city showed low to high levels of salinity contamination (Figure 4). This indicates that the leakage of landfill leachate should also be an important source for groundwater salinity contamination in NUA in the PRD because these landfills often lacked antiseepage measure and landfill leachate showed extremely high levels of TDS $[13,31]$.

\section{Conclusions}

Results showed that NBLs of TDS in groundwater units A to D were $688 \mathrm{mg} / \mathrm{L}, 432 \mathrm{mg} / \mathrm{L}, 321 \mathrm{mg} / \mathrm{L}$, and $99 \mathrm{mg} / \mathrm{L}$, respectively. The seawater intrusion was likely to be responsible for the much higher NBL-TDS in groundwater unit A than that in other groundwater units. By contrast, higher NBL-TDS in groundwater unit B than that in groundwater units $\mathrm{C}$ and $\mathrm{D}$ was probably attributed to the more strong interactions of water and soils/rocks in groundwater unit B in comparison with that in groundwater units $\mathrm{C}$ and $\mathrm{D}$. This was also likely to be the main reason for the much higher NBL-TDS in groundwater unit $\mathrm{C}$ than that in groundwater unit D.

The proportion of salinity contamination in groundwater unit $\mathrm{D}$ was much higher than that in other groundwater units. This may be attributed to the more coarse-grained media of vadose zone in groundwater unit D in comparison with other groundwater units. By contrast, a higher ratio of UA in groundwater unit $\mathrm{A}$ than that in groundwater units $\mathrm{B}$ and $\mathrm{C}$ was probably responsible for the higher proportion of salinity contamination in groundwater unit A in comparison with that in groundwater units B and C.

Groundwater salinity contamination in the PRD was positively correlated with the urbanization level. Furthermore, proportions of salinity contamination in $\mathrm{UA}^{2 \text { nd }}$ were much higher than that in $\mathrm{UA}^{3 \mathrm{rd}}$ regardless of groundwater units. By contrast, the proportion of salinity contamination in $\mathrm{UA}^{3 \mathrm{rd}}$ was also much higher than that in $\mathrm{UA}^{1 \text { st }}$ in both groundwater units $\mathrm{B}$ and $\mathrm{C}$ but contrary in groundwater unit A. Wastewater from TVE and industrial wastewater were likely to be the main sources for groundwater salinity contamination in the $\mathrm{PRD}$, and the wastewater leakage from sewer systems was one of the main pathways for groundwater salinity contamination in UA. Besides, sewage irrigation and leakage of landfill leachate were also important sources for groundwater salinity contamination in the PRD.

\section{Data Availability}

The data used to support the findings of this study are included within the article.

\section{Conflicts of Interest}

The authors declare that there are no conflicts of interest regarding the publication of this paper.

\section{Acknowledgments}

This research was supported by the Graduate Students Teaching Case of Hebei Province (KCJSZ2019092), the Postgraduate Innovation Funding Project of Hebei Province (CXZZSS2020115), the Fundamental Research Funds for Hunan Academy of Geology (no. 201904), and the China Geological Survey Grant (DD20160309).

\section{Supplementary Materials}

Table S1: socioeconomic data for the nine major cities of the PRD in 2006. Table S2: groundwater salinity contamination in UA formed in different periods in the Pearl River Delta. Figure S1: the expansion of urbanization in the PRD. (Supplementary Materials)

\section{References}

[1] A. Mukherjee, B. Scanlon, A. Aureli, S. Langan, H. Guo, and A. McKenzie, Global Groundwater: Source, Scarcity, Sustainability, Security and Solutions, Elsevier, Amsterdam, Netherlands, first edition, 2020.

[2] G. Huang, C. Liu, J. Sun, M. Zhang, J. Jing, and L. Li, “A regional scale investigation on factors controlling the groundwater chemistry of various aquifers in a rapidly urbanized area: a case study of the Pearl River Delta," Science of the Total Environment, vol. 625, pp. 510-518, 2018.

[3] G. Huang, C. Liu, Y. Zhang, and Z. Chen, "Groundwater is important for the geochemical cycling of phosphorus in rapidly urbanized areas: a case study in the Pearl River Delta," Environmental Pollution (Barking, Essex: 1987), vol. 260, Article ID 114079, 2020.

[4] F. Zhang, G. Huang, Q. Hou, C. Liu, Y. Zhang, and Q. Zhang, "Groundwater quality in the Pearl River Delta after the rapid expansion of industrialization and urbanization: distributions, main impact indicators, and driving forces," Journal of Hydrology, vol. 577, Article ID 124004, 2019.

[5] M. Zhang, G. Huang, C. Liu, Y. Zhang, Z. Chen, and J. Wang, "Distributions and origins of nitrate, nitrite, and ammonium in various aquifers in an urbanized coastal area, south China," Journal of Hydrology, vol. 582, Article ID 124528, 2020.

[6] X. Wu, L. Zhang, B. X. Hu, Y. Wang, and Z. Xu, "Isotopic and hydrochemical evidence for the salinity origin in the coastal aquifers of the Pearl River Delta, Guangzhou, China," Journal of Contaminant Hydrology, vol. 235, Article ID 103732, 2020. 
[7] Y. Wang and J. J. Jiao, "Origin of groundwater salinity and hydrogeochemical processes in the confined Quaternary aquifer of the Pearl River Delta, China," Journal of Hydrology, vol. 438-439, pp. 112-124, 2012.

[8] S. Sang, X. Zhang, H. Dai, B. X. Hu, H. Ou, and L. Sun, "Diversity and predictive metabolic pathways of the prokaryotic microbial community along a groundwater salinity gradient of the Pearl River Delta, China," Scientific Reports, vol. 8, Article ID 17317, 2018.

[9] B. Backman, D. Bodiš, P. Lahermo, S. Rapant, and T. Tarvainen, "Application of a groundwater contamination index in Finland and Slovakia," Environmental Geology, vol. 36, no. 1-2, pp. 55-64, 1998.

[10] Z. Jia, J. Bian, and Y. Wang, "Impacts of urban land use on the spatial distribution of groundwater pollution, Harbin City, Northeast China," Journal of Contaminant Hydrology, vol. 215, pp. 29-38, 2018.

[11] N. S. Rao and M. Chaudhary, "Hydrogeochemical processes regulating the spatial distribution of groundwater contamination, using pollution index of groundwater (PIG) and hierarchical cluster analysis (HCA): a case study," Groundwater for Sustainable Development, vol. 9, Article ID 100238, 2019.

[12] Q. Hou, Q. Zhang, G. Huang, C. Liu, and Y. Zhang, "Elevated manganese concentrations in shallow groundwater of various aquifers in a rapidly urbanized delta, south China," The Science of the Total Environment, vol. 701, Article ID 134777, 2020.

[13] G. Huang, C. Liu, L. Li, F. Zhang, and Z. Chen, "Spatial distribution and origin of shallow groundwater iodide in a rapidly urbanized delta: a case study of the Pearl River Delta," Journal of Hydrology, vol. 585, Article ID 124860, 2020.

[14] C. Li, X. Gao, Y. Liu, and Y. Wang, "Impact of anthropogenic activities on the enrichment of fluoride and salinity in groundwater in the Yuncheng Basin constrained by $\mathrm{Cl} / \mathrm{Br}$ ratio, $\delta^{18} \mathrm{O}, \delta^{2} \mathrm{H}, \delta^{13} \mathrm{C}$ and $\delta^{7} \mathrm{Li}$ isotopes," Journal of $\mathrm{Hy}$ drology, vol. 579, Article ID 124211, 2019.

[15] C. Li, X. Gao, S. Li, and J. Bundschuh, "A review of the distribution, sources, genesis, and environmental concerns of salinity in groundwater," Environmental Science and Pollution Research, vol. 27, no. 33, pp. 41157-41174, 2020.

[16] J. Griffioen, H. F. Passier, and J. Klein, "Comparison of selection methods to deduce natural background levels for groundwater units," Environmental Science \& Technology, vol. 42, no. 13, pp. 4863-4869, 2008.

[17] K. Hinsby, M. T. Condesso de Melo, and M. Dahl, "European case studies supporting the derivation of natural background levels and groundwater threshold values for the protection of dependent ecosystems and human health," Science of the Total Environment, vol. 401, no. 1-3, pp. 1-20, 2008.

[18] D. Ducci, M. T. C. de Melo, E. Preziosi, M. Sellerino, D. Parrone, and L. Ribeiro, "Combining natural background levels (NBLs) assessment with indicator kriging analysis to improve groundwater quality data interpretation and management," Science of the Total Environment, vol. 569-570, pp. 569-584, 2016.

[19] Y. Zong, W. W.-S. Yim, F. Yu, and G. Huang, "Late Quaternary environmental changes in the Pearl River mouth region, China," Quaternary International, vol. 206, no. 1-2, pp. 35-45, 2009.

[20] G. Huang, J. Sun, Y. Zhang, Z. Chen, and F. Liu, "Impact of anthropogenic and natural processes on the evolution of groundwater chemistry in a rapidly urbanized coastal area, South China," Science of the Total Environment, vol. 463-464, pp. 209-221, 2013.
[21] G. Huang, M. Zhang, C. Liu, L. Li, and Z. Chen, "Heavy metal(loid)s and organic contaminants in groundwater in the Pearl River Delta that has undergone three decades of urbanization and industrialization: distributions, sources, and driving forces," Science of the Total Environment, vol. 635, pp. 913-925, 2018.

[22] Guangdong Hydrogeological Second Team, Regional Hydrogeological Survey Report, Guangdong Hydrogeological Second Team, Guangzhou, China, 1981, in Chinese.

[23] X. Li, C. Tang, Y. Cao, and X. Li, "Carbon, nitrogen and sulfur isotopic features and the associated geochemical processes in a coastal aquifer system of the Pearl River Delta, China," Journal of Hydrology, vol. 575, pp. 986-998, 2019.

[24] Y. Wang, J. J. Jiao, and J. A. Cherry, "Occurrence and geochemical behavior of arsenic in a coastal aquifer-aquitard system of the Pearl River Delta, China," Science of the Total Environment, vol. 427-428, pp. 286-297, 2012.

[25] A. N. Analytical Methods Committee, "Using the Grubbs and Cochran tests to identify outliers," Analytical Methods, vol. 7, no. 19, pp. 7948-7950, 2015.

[26] K. S. Gundogdu and I. Guney, "Spatial analyses of groundwater levels using universal Kriging," Journal of Earth System Science, vol. 116, no. 1, pp. 49-55, 2007.

[27] Y. Wu, Y. Wang, and X. Xie, "Spatial occurrence and geochemistry of soil salinity in Datong basin, northern China," Journal of Soils and Sediments, vol. 14, no. 8, pp. 1445-1455, 2014.

[28] Guangdong Province Statistical Bureau, 2006 Statistical Yearbook of Guangdong Province, China Statistical Publisher House, Beijing, China, 2007.

[29] F. Larsen, L. V. Tran, H. Van Hoang, L. T. Tran, A. V. Christiansen, and N. Q. Pham, "Groundwater salinity influenced by Holocene seawater trapped in incised valleys in the Red River delta plain," Nature Geoscience, vol. 10, no. 5, pp. 376-381, 2017.

[30] Water Resources Department of Guangdong Province, Guangdong Water Resources Bulletin in 2006, Water Resources Department of Guangdong Province, Guangzhou, China, Chinese, 2007.

[31] G. Huang, Z. Chen, F. Liu, J. Sun, and J. Wang, "Impact of human activity and natural processes on groundwater arsenic in an urbanized area (South China) using multivariate statistical techniques," Environmental Science and Pollution Research, vol. 21, no. 22, pp. 13043-13054, 2014. 